\title{
Neuroprotective Effects of Scopoletin on Neuro-damage caused by Alcohol in Primary Hippocampal Neurons
}

\author{
Jina Lee ${ }^{*}$ and Hyun-Jeong Cho ${ }^{\dagger, * *}$ \\ Department of Biomedical Laboratory Science, College of Medical Science, \\ Konyang University, Daejeon 35365, Korea
}

\begin{abstract}
Excessive drinking of alcohol is known to be one of the main causes of various neurological diseases, such as Alzheimer's disease. Scopoletin is known to have anti-inflammatory and antioxidative properties, and to protect nerve cells. This study examined whether scopoletin inhibits the alcohol-induced apoptosis of primary hippocampal neurons, and how scopoletin regulates several factors associated with the caspase-mediated pathway. To achieve this, the cell viability and apoptosis rate of primary hippocampal neurons were measured by Cell Counting Kit- 8 and flow cytometry, respectively. Apoptosis-related protein expressions (Bax, Bid, caspase-3, caspase-9, and Poly (ADP-ribose) polymerase (PARP)) were analyzed by Western blotting, and the ANOVA method was used to confirm the significance of the measured results. As a result, scopoletin inhibited the expressions of alcohol-induced apoptosis and apoptosis-related proteins in primary hippocampal neurons. These results suggest that down-regulation of Bid, Bax, and cleaved caspase-9 expression induced by scopoletin down-regulates the expression of cleaved caspase-3, inhibits the expression of cleaved PARP, and finally, inhibits mitochondrial apoptotic pathways. The study suggests that scopoletin is worth developing as a candidate for neuroprotective agent.
\end{abstract}

Key Words: Apoptosis, Scopoletin, Primary hippocampal neuron, Bid, Bax, Caspase-9, Caspase-3, PARP

\section{INTRODUCTION}

When nerve cells in the brain die or do not function normally, memory and behavioral changes occur, and this is called dementia. Alzheimer's disease (AD), which is the most common dementia, is a degenerative brain disease. It is characterized by memory and cognitive ability decline (Barker et al., 2002; Kalaria et al., 2008; Wilson et al., 2012). Therefore, the hippocampus responsible for the storage function of memory has attracted attention in studies related to AD (Zarow et al., 2005; Hollands et al., 2016; MorenoJiménez et al., 2019). Also, AD is characterized by tangles of nerve fibers, amyloid plaques, and nerve loss. Neuronal loss is a common pathway in the degenerative process of $\mathrm{AD}$ and can be caused by various factors, for example, amyloid-beta plaques, inflammation, and oxidative stress (Baloyannis, 2006; Spires et al., 2006; Padurariu et al., 2010; Ciobica et al., 2011).

$\mathrm{AD}$ is caused for a variety of reasons, which include environmental, genetic, and lifestyle factors (Kalaria et al., 2008; Barnes and Yaffe, 2011). Excessive apoptosis plays a

Received: April 27, 2020 / Revised: May 21, 2020 / Accepted: June 4, 2020

* Graduate student, ${ }^{* *}$ Professor.

${ }^{\dagger}$ Corresponding author: Hyun-Jeong Cho. Department of Biomedical Laboratory Science, College of Medical Science, Konyang University, 158, Gwanjeodong-ro, Seo-gu, Daejeon 35365, Korea.

Tel: +82-42-600-8433, Fax: +82-42-600-8408, e-mail: hjcho@konyang.ac.kr

(C) The Korean Society for Biomedical Laboratory Sciences. All rights reserved.

(c) This is an Open Access article distributed under the terms of the Creative Commons Attribution Non-Commercial License (http://creativecommons.org/licenses/by-nc/3.0/) which permits unrestricted non-commercial use, distribution, and reproduction in any medium, provided the original work is properly cited. 
role in many neurological diseases, which include $\mathrm{AD}(\mathrm{Su}$ et al., 2001; Dickson, 2004; Das and Vasudevan, 2007). Alcoholism causes brain damage, including brain shrinkage, reduction in numbers of neurons, oxidative stress, mitochondrial damage, and apoptosis (Bonthius and West, 1990; Mann et al., 2001; Young et al., 2003; Han et al., 2005; Zhong et al., 2006). Recent studies have indicated that chronic alcohol consumption increases the expression of genes associated with amyloid-beta production. The accumulation of amyloidbeta can induce neuronal cell death through the caspase pathway (Takahashi et al., 2002; Kim et al., 2011; Han et al., 2017). Caspase-mediated apoptosis has been known to be a significant mediator of cell death in some neurodegenerative diseases (Li et al., 2008).

In this study, we used scopoletin, which is a coumarin that is isolated from several plant species. This compound plays many roles in health treatment, such as inflammation, rheumatic pains, leprosy, and cardiovascular and neuromuscular actions (Carpinella et al., 2005; Ding et al., 2008; Gnonlonfin et al., 2012; Pandy et al., 2014). According to recent research, Morinda citrifolia fruit extract (MCE) with scopoletin mitigates skeletal muscle damage through antiapoptosis (Narasimhan et al., 2016). Scopoletin suppresses apoptosis in the neuronal cell through the prevention of oxidative stress (Narasimhan et al., 2019). It also inhibits acetylcholinesterase enzyme ( $\mathrm{AChE}$ ) that could play a key role in accelerating amyloid-beta plaque deposition (Inestrosa et al., 1996; Rollinger et al., 2004).

$\mathrm{AD}$ is a degenerative brain disease, so neuronal cells are used in research. Among them, primary neuronal cells are they can produce results close to in vivo research. In general, when performing experiments related to $\mathrm{AD}$, inflammation, and apoptosis caused by substances such as amyloid-beta and alcohol are measured (Calissano et al., 2009; Fonseca et al., 2009; Scuderi et al., 2014). We used a model of alcoholinduced apoptosis in the hippocampal neurons most associated with $\mathrm{AD}$.

In this present study, we assumed that scopoletin has a protective effect on apoptosis to primary hippocampal cells caused by alcohol, and investigate how scopoletin regulates several factors that are related to the caspase-mediated pathway. So, we measured cell viability, cell apoptosis rate, and the level of protein (Bax, Bid, Caspase-3, Caspase-9, and Poly (ADP-ribose) polymerase (PARP)) expression associated with apoptosis in the primary hippocampal neuron. The purpose of this study is to clarify the protection of scopoletin against alcohol-induced apoptosis of primary hippocampal neurons. This may provide a theoretical basis for scopoletin for clinical treatment for neuro-damage caused by alcohol.

\section{MATERIALS AND METHODS}

\section{Materials}

Scopoletin, Dimethyl sulfoxide (DMSO), and Accumax ${ }^{\mathrm{TM}}$ solution were bought from Sigma-Aldrich (St. Louis, MO, USA). Anti-Bax, anti-caspase-9, anti-caspase-3, anti-PARP, anti-mouse IgG-horseradish peroxidase (HRP) conjugate, anti-rabbit IgG HRP antibodies, and lysis buffer were purchased from Cell Signaling Technology (Beverly, MA, USA). $\beta$-actin was bought from Santa Cruz Biotechnology (Santa Cruz, CA, USA). Anti-Bid was purchased from GeneTex (Irvine, CA, USA). Polyvinylidene difluoride (PVDF) membrane and Enhanced chemiluminescence (ECL) solution were purchased from GE Health Care (Chalfont St. Giles, Buckinghamshire, UK). Primary hippocampal neurons from Sprague-Dawley rat were obtained from KOATECH (Gyeonggi-do, Korea). Neuronal basal media, B-27 Supplement, Penicillin (100 U/mL), Streptomycin $(100 \mu \mathrm{g} / \mathrm{mL})$, GlutaMAX, and Sodium pyruvate were purchased from Gibco (Gaithersburg, MD, USA). Cell viability was measured using Cell Counting Kit-8 (Dojindo Laboratories, Kumamoto, Japan). To measure primary hippocampal neurons apoptosis, FITC annexin V apoptosis Detection Kit (BD Bioscience, Franklin Lakes, NJ, USA) was used.

\section{Cell culture}

Primary hippocampal neurons were prepared from Sprague-Dawley rat embryos at embryonic day 21. Brains were removed after decapitation, meninges stripped, and the collected hippocampus incubated with Accumax ${ }^{\mathrm{TM}}$ solution at $37^{\circ} \mathrm{C} \mathrm{CO}_{2}$ incubator for $15 \mathrm{~min}$. Afterwards, brain tissue was washed with HBSS three times, and dissociated by pipetting into starter media (Neuronal basal media with B27, 
glutaMAX, sodium pyruvate, penicillin-streptomycin). Cells were counted by hemocytometer, and seeded at $3 \times 10^{5}$ in 6-well plates. Before use, the plates were pretreated with poly-L-lysine $\left(0.5 \% \mathrm{w} / \mathrm{v}\right.$ in autoclaved TDW) at $37^{\circ} \mathrm{C}$ for at least $1 \mathrm{~h}$. Cultures were kept at $37^{\circ} \mathrm{C}$ and $5 \% \mathrm{CO}_{2}$, and half of the medium was replaced twice a week. All animal experiments were carried out according to the guidelines of the Institutional Animal Care and Use Committee of Konyang University (P-20-08-E-01) (Daejeon, South Korea).

\section{Cell viability analysis}

Cell viability was measured using the Cell Counting Kit-8 (CCK-8, Dojindo, Kumamoto, Japan). The cells were seeded into 96-well plates $\left(1 \times 10^{4}\right.$ cells $)$, and cultured for 14 days. Afterwards, cells were pretreated for $3 \mathrm{~h}$ with various concentrations of scopoletin, and treated without or with $400 \mathrm{mM}$ alcohol. After incubation for $24 \mathrm{~h}, 10 \mu \mathrm{L}$ of CCK-8 solution was added to each well, and the cells incubated for $3 \mathrm{~h}$. Scopoletin was dissolved in a final concentration of $\leq 0.1 \%$ with DMSO. DMSO is not affected the results (data not shown).

The fluorescence intensity of the plates was then measured at $450 \mathrm{~nm}$ by SpectraMax iD3 microplate reader (Molecular Devices, Sunnyvale, CA, USA).

\section{Western blot analysis}

Cells were lysed on ice in RIPA buffer for $20 \mathrm{~min}$. They were then centrifuged, and the supernatant containing the protein $(5 \mu \mathrm{g})$ was mixed with sample buffer, and boiled at $95^{\circ} \mathrm{C}$ for $5 \mathrm{~min}$. Protein concentrations were measured using $\mathrm{DC}^{\mathrm{TM}}$ Protein Assay (Bio-Rad Laboratories, USA). The samples were isolated by $12 \%$ SDS-polyacrylamide gel electrophoresis, and transferred onto polyvinylidene fluoride (PVDF) membranes. After blocking with $1 \times$ blocking buffer (BioFact Biofactory, Daejeon, Korea) at room temperature for $1 \mathrm{~h}$, the membranes were incubated overnight with primary antibodies at $4{ }^{\circ} \mathrm{C}$. Next day, membranes were incubated with secondary antibodies, and detected by ECL. The blots were analyzed using ImageQuant ${ }^{\mathrm{TM}}$ LAS 500 (GE Healthcare, Chicago, IL, USA). The dilutions for anti-caspase -9, anti-caspase-3, anti-Bid, anti-Bax, anti-PARP, $\beta$-actin, and anti-mouse IgG-horseradish peroxidase (HRP) conjugate, anti-rabbit IgG HRP antibodies were 1:2,000. Scopoletin was dissolved in a final concentration of $\leq 0.1 \%$ with DMSO. DMSO is not affected the results (data not shown).

\section{Detection of apoptosis}

Apoptosis was detected using FITC annexin V apoptosis Detection Kit (BD). The cells were seeded into 6-well plates $\left(3 \times 10^{5}\right)$, and cultured for 14 days. Next, cells were pretreated for $3 \mathrm{~h}$ with various concentrations of scopoletin, and were treated without or with $400 \mathrm{mM}$ alcohol. After incubation for $24 \mathrm{~h}$, the cells were washed using PBS buffer, and then resuspended in binding buffer. Cells were next incubated with FITC Annexin V and Propidium iodide (PI) for $15 \mathrm{~min}$ in the dark. Binding buffer was added, and cell apoptosis was analyzed by BD Accuri ${ }^{\mathrm{TM}}$ C6 Plus Flow Cytometer (BD Bioscience, Franklin Lakes, NJ, USA). Scopoletin was dissolved in a final concentration of $\leq 0.1 \%$ with DMSO. DMSO is not affected the results (data not shown).

\section{Statistical analysis}

The experimental results are presented as the mean \pm S.D., and statistical analysis was performed by one-way analysis of variance (ANOVA). The results with $P$-value $<$ 0.05 were considered statistically significant.

\section{RESULTS}

\section{Effects of scopoletin on cell viability in alcohol-treated primary hippocampal neurons}

Alcohol induces cell death in the neuron in a concentration-dependent manner (Fig. 1A). Therefore, reducing the neuron cell death by scopoletin might be protective against alcohol-induced neuro-damage. When primary hippocampal neurons were exposed to $400 \mathrm{mM}$ alcohol, the cell survival rate was decreased to $65 \%$ over the control $(100 \%)$, whereas scopoletin-enhanced cell viability increased to $82 \%$ at $20 \mu \mathrm{M}$ (Fig. 1C). These results show that primary hippocampal neuron death is suppressed by scopoletin in a concentrationdependent manner. Additionally, scopoletin is confirmed to have a non-cytotoxic effect in a dose-dependent manner (Fig. 1B). 
A

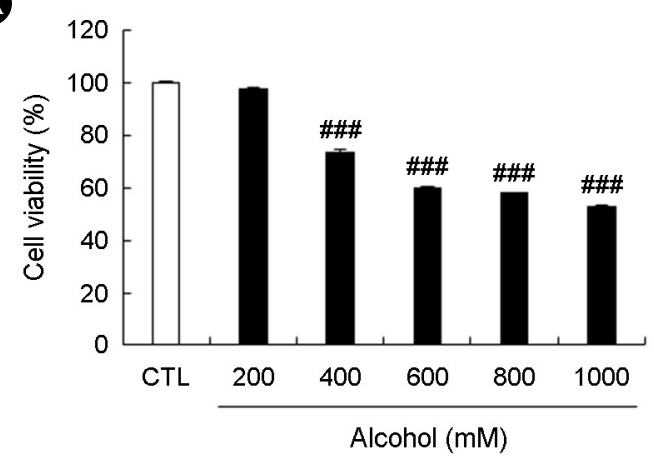

B

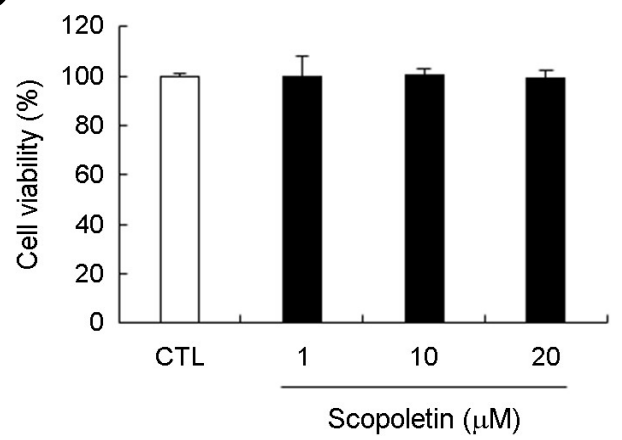

Effects of scopoletin on Bid, Bax, caspase-9, caspase-3, and PARP levels in alcohol-treated primary hippocampal neurons

Alcohol is known to induce neuronal cell apoptosis. When primary hippocampal neurons were treated with alcohol for $24 \mathrm{~h}$, the level of the apoptosis proteins Bid and Bax were significantly increased by 362 and $155 \%$, respectively, compared to those of the control. In contrast, pre-treatment with 1,10 , and $20 \mu \mathrm{M}$ of scopoletin was significantly reduced (Figs. 2A and 2B). Furthermore, 1, 10, and $20 \mu \mathrm{M}$ of scopoletin reduced the level of apoptosis protein cleaved caspase- 9 and cleaved caspase- 3 on the alcohol-treated primary hippocampal neurons. Once primary hippocampal neurons were treated with alcohol for $24 \mathrm{~h}$, the level of the apoptosis protein cleaved caspase 9 and cleaved caspase 3 were increased by 270 and $272 \%$, respectively, compared to those levels of control. Contrariwise, pre-treatment with 1, 10, and $20 \mu \mathrm{M}$ scopoletin significantly reduced these levels in a dose-dependent manner (Figs. 2C and 2D). Also, alcoholtreated neurons increased cleaved PARP. When primary

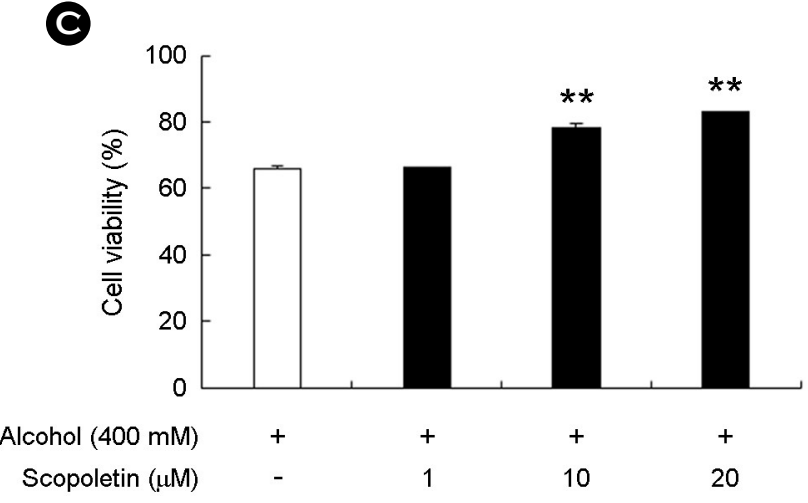

Fig. 1. Effects of scopoletin on cell viability in alcohol-treated primary hippocampal neuron. (A) Effect of alcohol on primary hippocampal neurons. (B) Effects of the scopoletin on primary hippocampal neurons. (C) Effects of scopoletin on $400 \mathrm{mM}$ alcoholtreated primary hippocampal neurons. The cells were seeded into 96-well plates $\left(1 \times 10^{4}\right.$ cells $)$. Scopoletin was pretreated in various concentrations. After $3 \mathrm{~h}, 400 \mathrm{mM}$ alcohol was treated for $24 \mathrm{~h}$, and $10 \mu \mathrm{L}$ of CCK- 8 reagent was added to each well. The 96-well plates were read by SpectraMax iD3 microplate reader (Molecular Devices, CA, USA) at $450 \mathrm{nM}$. Data are presented as mean \pm S.D. $(\mathrm{n}=3)$. ${ }^{\#} P<0.001$ compared with untreated cells; ${ }^{* *} P<0.01$ compared to alcohol-treated cells.

hippocampal neurons were treated with alcohol for $24 \mathrm{~h}$, apoptosis protein cleaved PARP level was increased, compared to those of the control $(127 \%)$. In contrast, pretreatment with 1,10 , and $20 \mu \mathrm{M}$ of scopoletin reduced levels in a dose-dependent manner (Fig. 2E).

\section{Effects of scopoletin on apoptosis in alcohol-treated pri-} mary hippocampal neurons

Fig. 3 shows that when treated by $400 \mathrm{mM}$ alcohol, the percentage of annexin V + PI loaded apoptotic cells increased to $6.1 \%$. However, scopoletin pre-treatment at 1,10 , and $20 \mu \mathrm{M}$ significantly reduced cell apoptosis in a dosedependent manner at 5.1, 3.5, and 3.4\%, respectively. The results suggest that the anti-apoptosis activity of scopoletin in alcohol-treated primary hippocampal neurons was due to the reduction of apoptotic cells.

\section{DISCUSSION}

Rat primary hippocampal neurons are frequently used in experiments related to neuronal apoptosis and neurodege- 

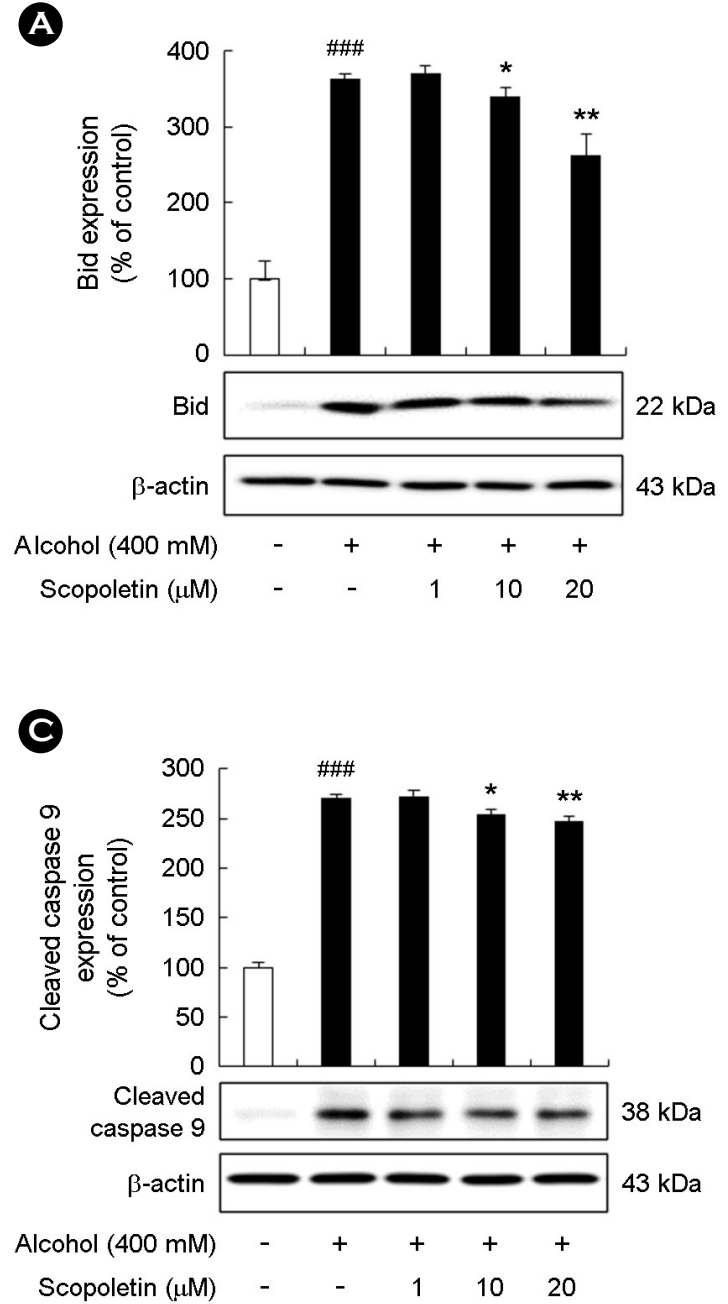

E

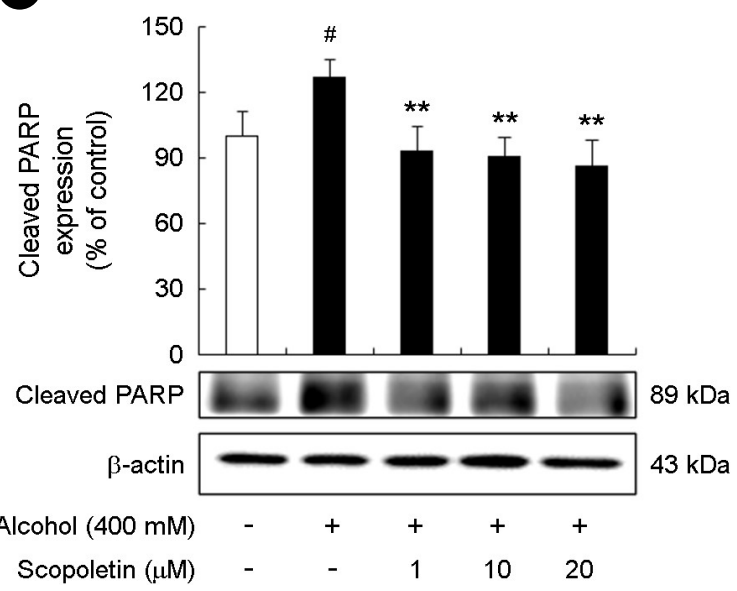

B

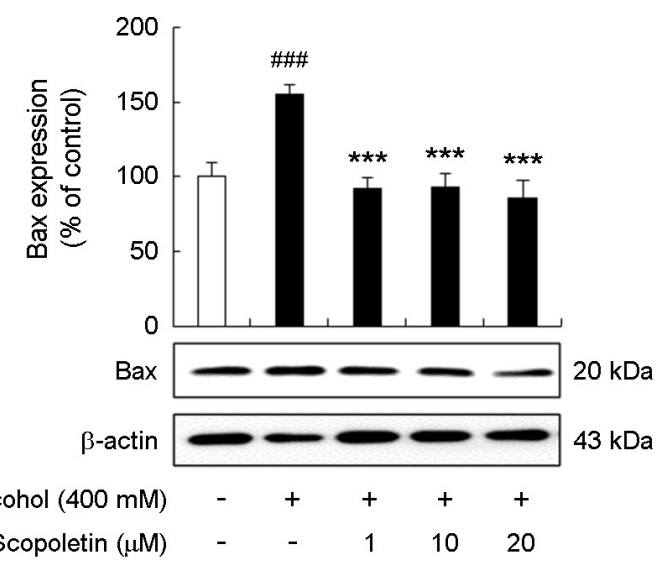

(D)

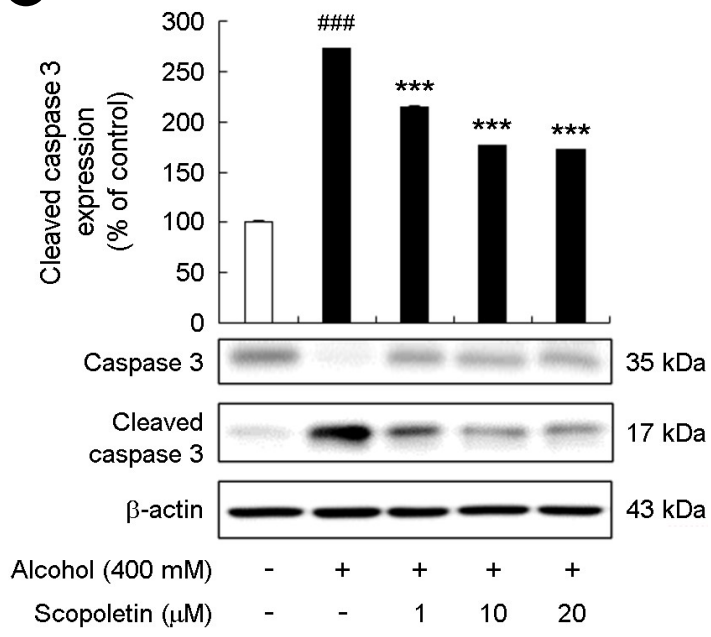

Fig. 2. Effects of scopoletin on Bid, Bax, caspase-9, caspase-3, and PARP levels in the alcohol-treated primary hippocampal neuron. (A) Effect of scopoletin on Bid activity. (B) Effect of scopoletin on Bax activity. (C) Effect of scopoletin on Cleaved caspase 9 activity. (D) Effect of scopoletin on Cleaved caspase 3 activity. (E) Effect of scopoletin on Cleaved PARP activity. Primary hippocampal neurons were pre-incubated with $0,1,10$, and $20 \mu \mathrm{M}$ scopoletin for $3 \mathrm{~h}$, and then treated with 400 $\mathrm{mM}$ alcohol or nonalcohol for $24 \mathrm{~h}$. Data are expressed as mean \pm S.D. $(\mathrm{n}=3) .{ }^{\#} P<0.05,{ }^{\# \#} P<0.001$, compared to untreated cells; ${ }^{*} P<0.05,{ }^{* *} P<0.01,{ }^{* * *} P<0.001$, compared to alcohol-treated cells. nerative disease (Tamatani et al., 1999; Murphy et al., 2000; Zhao et al., 2004). One of the main principles of alcohol that damages the central nervous system and kills neurons is to increase reactive stress species (ROS) and cause mito- 
(A)

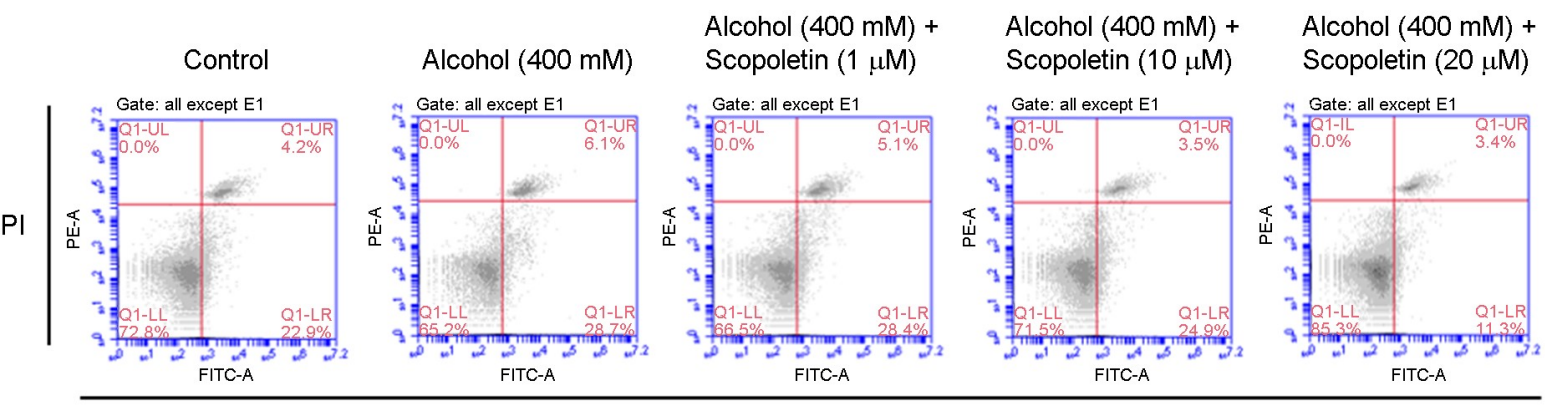

Annexin V-FITC

B

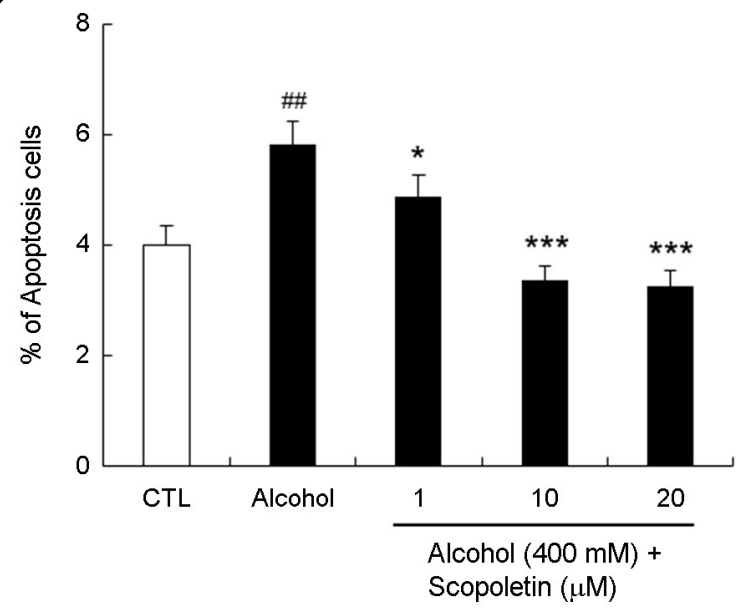

Fig. 3. Effects of scopoletin on alcohol-induced apoptosis in primary hippocampal neurons. (A) FACS detection with double staining of annexin $\mathrm{V}$ and propidium iodide (PI). (B) Quantification of apoptosis rate ground on FACS results. Annexin V + PI loaded cells (5 $\times 10^{4}$ cells/test) were preincubated with $0,1,10$, and $20 \mu \mathrm{M}$ scopoletin, and treated with $400 \mathrm{mM}$ alcohol or nonalcohol. Data are expressed as mean \pm S.D. $(n=3)$. ${ }^{\#} P<0.01$ compared to untreated cells; ${ }^{*} P<0.05,{ }^{* * *} P<$ 0.001 , compared to alcohol-treated cells. chondrial DNA damage, leading to neuronal cell death and necrosis (Fadda and Rossetti, 1998). According to recent studies, many compounds extracted from natural products play an important role in protection against damage to neuronal cells. Among them, scopoletin has been known to have a protective effect on neuronal damage against oxidative stress (Inestrosa et al., 1996). Therefore, it can be beneficial for alcohol-induced neurotoxicity. However, the molecular mechanisms of scopoletin on alcohol-induced neuronal damage have not yet been explained.

To investigate the neuroprotective effect of scopoletin on alcohol-induced apoptosis in primary hippocampus neurons, preliminary experiments in this study were conducted to induce cell death of primary hippocampus neurons using $400 \mathrm{mM}$ alcohol. For cell viability, the optimum dose of scopoletin was experimented with, and cell apoptosis measured. Expression of Bax, Bid, cleaved caspase-9, cleaved caspase-3, and cleaved PARP further clarified the mech- anisms. The results show a marked decrease in cell death and cell viability in primary hippocampal neurons treated with $400 \mathrm{mM}$ alcohol. All these results prove that the model is successful. In contrast, treatment with scopoletin presented the inhibitory effect of primary hippocampal neurons on alcohol-induced cell death. The concentration of scopoletin was conducted up to $30 \mu \mathrm{M}$ (Narasimhan et al., 2019), and the experiment showed the most effect at $20 \mu \mathrm{M}$. Oxidative stress leading to mitochondrial dysfunction plays a significant role in the alcohol-induced neuronal damage mechanism, and one of the major factors of neuronal cell death is the potential loss of mitochondrial membrane (Fadda and Rossetti, 1998). Thus, when scopoletin inhibits the apoptosis of primary hippocampal neurons, it may be the result of protecting mitochondrial membrane from potential loss. The results of this experiment show that alcohol-treated primary hippocampal neurons increased the expression of cleaved caspase3 , whereas scopoletin pretreated neurons effectively inhibited 
cleaved caspase-3.

Bcl-2 family proteins play an important role in cell apoptosis. When apoptosis occurs through the extrinsic pathway death receptor, activated caspase- 8 activates $\mathrm{BH} 3$ interacting-domain death agonist (Bid), which a member of the Bcl-2 protein family. Activated Bid enters the intrinsic pathway, and activates Bcl-2-associated X protein (Bax); activated Bax can penetrate into mitochondrial outer membranes, which leads to apoptosis. So, when confirming the apoptosis of caspase- 3 expression, it is effective to confirm the Bid and Bax levels.

In the present study, scopoletin inhibited Bid and Bax, and suppressed caspase-9 cleavage by caspase-9 activation. Thus, the expression of cleaved caspase- 3 and the expression of cleaved PARP were suppressed. This indicates that scopoletin inhibits caspase-3 by inhibiting Bid, Bax, and caspase-9, and reduces PARP cleaved by caspase-3. Apoptosis has extrinsic and intrinsic pathways. Mitochondria play an important role in intrinsic pathways apoptosis. Cytochrome $\mathrm{c}$ exits between the apoptotic pores formed by Bax, bak, etc., migrates to the cytoplasm and binds to apafl and caspase-9 to form apoptosomes. We have experimentally confirmed that scopoletin has an anti-apoptotic effect through the intrinsic pathway. In alcohol-induced apoptosis, scopoletin initiates the anti-apoptosis effect by inhibiting the Bid that links extrinsic and intrinsic pathway apoptosis. Also, by inhibiting Bax, apoptotic pore formation is suppressed, and caspase-9 activity is suppressed to suppress apoptosome formation. It inhibits the activity of caspase- 9 and inhibits the activity of caspase- 3 by the sequential cascade. These results suggest that down-regulations of Bid, Bax, and caspase-9 activation by scopoletin suppress caspase- 3 activation, cleavage of PARP, and finally inhibit mitochondrial apoptosis pathways. This shows the protective mechanism of scopoletin on alcohol-induced apoptosis in primary hippocampal neurons. This data was obtained from in vitro experiments, and it is necessary to examine the scopoletin effect on alcohol-induced neurotoxicity rodent models. Nevertheless, the study presents novel evidence that scopoletin can be applied as a candidate for neuroprotection.

\section{ACKNOWLEDGEMENT}

This research was supported by the Basic Science Research Program through the National Research Foundation of Korea (NRF), funded by the Ministry of Education, Science and Technology (2016R1C1B2007025); and by the National Dementia Research and Development Program of the Korea Health Industry Development Institute (KHIDI), funded by the Korean government (Ministry of Health and Welfare) (HI18C1671).

\section{CONFLICT OF INTEREST}

The authors declare no conflict of interest.

\section{REFERENCES}

Baloyannis SJ. Mitochondrial alterations in alzheimer's disease. Journal of Alzheimer's Disease. 2006. 9: 119-126.

Barker WW, Luis CA, Kashuba A, Luis M, Harwood DG, Loewenstein D, Waters C, Jimison P, Shepherd E, Sevush S, Graff-Radford N, Newland D, Todd M, Miller B, Gold M, Heilman K, Doty L, Goodman I, Robinson B, Pearl G, Dickson D, Duara R. Relative frequencies of alzheimer disease, lewy body, vascular and frontotemporal dementia, and hippocampal sclerosis in the state of florida brain bank. Alzheimer Disease and Associated Disorders. 2002. 16: 203-212.

Barnes DE, Yaffe K. The projected impact of risk factor reduction on alzheimer's disease prevalence. Lancet Neurology. 2011. 10: 819-828

Bonthius DJ, West JR. Alcohol-induced neuronal loss in developing rats: increased brain damage with binge exposure. Alcoholism: Clinical and Experimental Research. 1990. 14: 107-118.

Calissano P, Matrone C, Amadoro G Apoptosis and in vitro alzheimer's disease neuronal models. Communicative \& Integrative Biology. 2009. 2: 163-169.

Carpinella MC, Ferrayoli CG, Palacios SM. Antifungal synergistic effect of scopoletin, a hydroxycoumarin isolated from melia azedarach 1. fruits. Journal of Agricultural and Food Chemistry. 2005. 53: 2922-2927.

Ciobica A, Padurariu M, Bild W, Stefanescu C. Cardiovascular risk factors as potential markers for mild cognitive impairment and alzheimer's disease. Psychiatria Danubina. 2011. 23: 340 -346 .

Das SK, Vasudevan DM. Alcohol-induced oxidative stress. Life Sciences. 2007. 81: 177-187. 
Dickson DW. Apoptotic mechanisms in alzheimer neurofibrillary degeneration: cause or effect?. The Journal of Clinical Investigation. 2004. 114: 23-27.

Ding Z, Dai Y, Hao H, Pan R, Yao X, Wang Z. Anti-inflammatory effects of scopoletin and underlying mechanisms. Pharmaceutical Biology. 2008. 46: 854-860.

Fadda F, Rossetti ZL. Chronic ethanol consumption: from neuroadaptation to neurodegeneration. Progress in Neurobiology. 1998. 56: 385-431.

Fonseca ACRG, Proenca T, Resende R, Oliveira CR, Pereira CMF. Neuroprotective effects of statins in an in vitro model of alzheimer's disease. Journal of Alzheimer's Disease. 2009. 17: 503-517.

Gnonlonfin GJB, Sanni A, Brimer L. Review scopoletin - a coumarin phytoalexin with medicinal properties. Critical Reviews in Plant Sciences. 2012. 31: 47-56.

Han JY, Joo Y, Kim YS, Lee YK, Kim HJ, Cho GJ, Choi WS, Kang SS. Ethanol induces cell death by activating caspase-3 in the rat cerebral cortex. Molecules and Cells. 2005. 20: 189-195.

Han X, Hu Y, Yang Z, Jiang L, Shi S, Li Y, Guo M, Wu H, Wan Y. Amyloid $\beta-42$ induces neuronal apoptosis by targeting mitochondria. Molecular Medicine Reports. 2017. 16: 4521-4528.

Hollands C, Bartolotti N, Lazarov O. Alzheiemr's disease and hippocampal adult neurogenesis; exploring shared mechanisms. Frontiers in Neuroscience. 2016. 10: 178.

Inestrosa NC, Alvarez A, Pérez CA, Moreno RD, Vicente M, Linker C, Casanueva OI, Soto C, Garrido J. Acetylcholinesterase accelerates assembly of amyloid- $\beta$-peptides into alzheimer's fibrils: possible role of the peripheral site of the enzyme. Neuron. 1996. 16: 881-891.

Kalaria RN, Maestre GE, Arizaga R, Friedland RP, Galasko D, Hall K, Luchsinger JA, Ogunniyi A, Perry EK, Potocnik F, Prince M, Stewart R, Wimo A, Zhang Z, Antuono P. Alzheimer's disease and vascular dementia in developing countries: prevalence, management, and risk factors. The Lancet Neurology. 2008. 7: 812-826.

Kim S, Jeong H, Yang S, Choi S, Seo M, Yun Y, Choi Y, Baik S, Park J, Gwon A, Yang D, Lee C, Lee S, Park K, Jo D. Effects of chronic alcohol consumption on expression levels of app and aß-producing enzymes. BMB Reports. 2011. 44: 135-139.

Li X, Cheng W, Li J, Guo X, Guo C, Meng X, Sun S, Wang L. Protective effect of estrogen on apoptosis in a cell culture model of parkinson's disease. Clinical and Investigative Medicine. 2008. 31: E258-E264.
Mann K, Agartz I, Harper C, Shoaf S, Rawlings RR, Momenan R, Hommer DW, Pfefferbaum A, Sullivan EV, Anton RF, Drobes DJ, George MS, Bares R, Machulla HJ, Mundle G, Reimold M, Heinz A. Neuroimaging in alcoholism: ethanol and brain damage. Alcoholism: Clinical and Experimental Research. 2001. 25: 104S-109S.

Moreno-Jiménez EP, Flor-García M, Terreros-Roncal J, Rábano A, Cafini F, Pallas-Bazarra N, Ávila J, Llorens-Martín M. Adult hippocampal neurogenesis is abundant in neurologically healthy subjects and drops sharply in patients with alzheimer's disease. Nature Medicine. 2019. 24: 554-560.

Murphy DD, Rueter SM, Trojanowski JQ, Lee VM. Synucleins are developmentally expressed, and alpha-synuclein regulates the size of the presynaptic vesicular pool in primary hippocampal neurons. Journal of Neuroscience. 2000. 20: 3214 -3220 .

Narasimhan KKS, Jayakumar D, Velusamy P, Srinivasan A, Mohan T, Ravi DB, Uthamaraman S, Sathyamoorthy YK, Rajasekaran NS, Periandavan K. Morinda citrifolia and its active principle scopoletin mitigate protein aggregation and neuronal apoptosis through augmenting the $\mathrm{dj}-1 / \mathrm{nrf} 2 /$ are signaling pathway. Oxidative Medicine and Cellular Longevity. 2019. 2019: 1-13.

Narasimhan KKS, Paul L, Sathyamoorthy YK, Srinivasan A, Chakrapani LM, Singh A, Ravi DB, Krishnan TR, Velusamy P, Kaliappan K, Radhakrishnan R, Periandavan K. Amelioration of apoptotic events in the skeletal muscle of intra-nigrally rotenone-infused parkinsonian rats by morinda citrifolia up-regulation of bcl-2 and blockage of cytochrome c release. Food \& Function. 2016. 7: 922-937.

Padurariu M, Ciobica A, Hritcu L, Stoica B, Bild W, Stefanescu C. Changes of some oxidative stress markers in the serum of patients with mild cognitive impairment and alzheimer's disease. Neuroscience Letters. 2010. 469: 6-10.

Pandy V, Narasingam M, Kunasegaran T, Murugan DD, Mohamed Z. Effect of noni (morinda citrifolialinn.) fruit and its bioactive principles scopoletin and rutin on rat vas deferens contractility: an ex vivo study. The Scientific World Journal. 2014. 2014: 1-11.

Rollinger JM, Hornick A, Langer T, Stuppner H, Prast H. Acetylcholinesterase inhibitory activity of scopolin and scopoletin discovered by virtual screening of natural products. Journal of Medicinal Chemistry. 2004. 47: 6248-6254.

Scuderi C, Stecca C, Bronzuoli MR, Rotili D, Valente S, Mai A, Steardo L. Sirtuin modulators control reactive gliosis in an in 
vitro model of alzheimer's disease. Frontiers in Pharmacology. 2014. 5:89.

Spires TL, Orne JD, Santacruz K, Pitstick R, Carlson GA, Ashe KH, Hyman BT. Region-specific dissociation of neuronal loss and neurofibrillary pathology in a mouse model of tauopathy. Neurobiology. 2006. 168: 1598-1607.

$\mathrm{Su}$ JH, Zhao M, Anderson AJ, Srinivasan A, Cotman CW. Activated caspase- 3 expression in alzheimer's and aged control brain: correlation with alzheimer pathology. Brain Research. 2001. 898: 350-357.

Takahashi RH, Milner TA, Li F, Nam EE, Edgar MA, Yamaguchi $\mathrm{H}$, Beal MF, Xu H, Greengard P, Gouras GK. Intraneuronal alzheimer aß42 accumulates in multivesicular bodies and is associated with synaptic pathology. The American Journal of Pathology. 2002. 161: 1869-1879.

Tamatani M, Che YH, Matsuzaki H, Ogawa S, Okado H, Miyake S, Mizuno T, Tohyama M. Tumor necrosis factor induces bcl-2 and bcl-x expression through nfkb activation in primary hippocampal neurons. Journal of Biological Chemistry. 1999. 274: 8531-8538.

Wilson RS, Segawa E, Boyle PA, Anagnos SE, Hizel LP, Bennett DA. The natural history of cognitive decline in alzheimer's disease. Psychology and Aging. 2012. 27: 1008-1017.
Young C, Klocke BJ, Tenkova T, Choi J, Labruyere J, Qin Y, Holtzman DM, Roth KA, Olney JW. Ethanol-induced neuronal apoptosis in vivo requires bax in the developing mouse brain Cell Death and Differentiation. 2003. 10: 1148-1155.

Zarow C, Vinters HV, Ellis WG, Weiner MW, Mungas D, White L, Chui HC. Correlates of hippocampal neuron number in alzheimer's disease and ischemic vascular dementia. Ann Neurol. 2005. 57: 896-903.

Zhao L, Wu T, Brinton RD. Estrogen receptor subtypes alpha and beta contribute to neuroprotection and increased bcl-2 expression in primary hippocampal neurons. Brain Research. 2004. 1010: 22-34.

Zhong J, Yang X, Yao W, Lee W. Lithium protects ethanol-induced neuronal apoptosis. Biochemical and Biophysical Research Communications. 2006. 305: 905-910.

https://doi.org/10.15616/BSL.2020.26.2.57

Cite this article as: Lee J, Cho HJ. Neuroprotective Effects of Scopoletin on Neuro-damage caused by Alcohol in Primary Hippocampal Neurons. Biomedical Science Letters. 2020. 26: 57-65. 